\title{
Serum lipid profiles and glycemic control in adolescents and young adults with type 1 diabetes mellitus
}

\author{
Shin-Hee Kim, MD, \\ In-Ah Jung, MD, \\ Yeon Jin Jeon, MD, \\ Won Kyoung Cho, MD, PhD, \\ Kyoung Soon Cho, MD, \\ So Hyun Park, MD, PhD, \\ Min Ho Jung, MD, PhD, \\ Byoung Kyu Suh, MD, PhD \\ Department of Pediatrics, College of \\ Medicine, The Catholic University of \\ Korea, Seoul, Korea
}

Purpose: We aimed to investigate serum lipid profiles and glycemic control in adolescents and young adults with type 1diabetes mellitus (T1DM).

Methods: This cross-sectional study included 29 Korean young adults and adolescents with T1DM. The median age was 17 years (range, 10-25 years) and 18 $(62.1 \%)$ were female. We compared the lipid profiles of patients with dyslipidemia and those without dyslipidemia. Correlations between glycosylated hemoglobin (HbA1c) and lipid profiles (total cholesterol [TC], low-density lipoprotein cholesterol [LDL-C], high-density lipoprotein cholesterol [HDL-C], and triglyceride [TG]) were determined by linear regression analysis.

Results: Of the 29 patients with T1DM, 11 (37.9\%) were classified as having dyslipidemia due to the following lipid abnormality: $\mathrm{TC} \geq 200 \mathrm{mg} / \mathrm{dL}$ in 8 patients, LDL-C $\geq 130 \mathrm{mg} / \mathrm{dL}$ in 4 patients, TG $\geq 150 \mathrm{mg} / \mathrm{dL}$ in 2 patients, and HDL-C $\leq 35$ $\mathrm{mg} / \mathrm{dL}$ in 2 patients. Compared to patients without dyslipidemia, patients with dyslipidemia were more likely to have higher values of $\mathrm{HbA} 1 \mathrm{c}$ (median, 10.6\%; range, $7.5 \%-12.3 \%$ vs. median, $8.0 \%$; range, $6.6 \%-10.0 \% ; P=0.002$ ) and a higher body mass index $z$ score (median, 0.7 ; range, -0.57 to 2.6 vs. median, -0.4 ; range, -2.5 to $2.2 ; P=0.02)$. HbA1c levels were positively correlated with TC $(P=0.03$, $\left.R^{2}=0.156\right)$ and TG $\left(P=0.005, R^{2}=0.261\right)$.

Conclusion: A substantial proportion of adolescents and young adults with T1DM had dyslipidemia. We found a correlation between poor glycemic control and poor lipid profiles in those patients.

Keywords: Diabetes mellitus, Dyslipidemia, Glycemic index, Prevalence, Young adult

\section{Introduction}

Received: 15 July, 2014

Revised: 17 September, 2014

Accepted: 26 September, 2014

Address for correspondence:

Min Ho Jung, MD, PhD

Department of Pediatrics, Yeouido

St. Mary's Hospital, The Catholic

University of Korea College of

Medicine, 10 63(yuksam)-ro,

Yeongdeungpo-gu, Seoul 150-713, Korea

Tel: +82-2-3779-1131

Fax: +82-2-783-2589

E-mail: jmhpe@catholic.ac.kr

\section{Introduction}

Hyperglycemia and dyslipidemia are metabolic abnormalities commonly found in young patients with type 1 diabetes mellitus (T1DM), and both increase the risk of cardiovascular disease, the leading cause of mortality in this population ${ }^{1)}$. Many studies have shown that microvascular changes and precursors of atherosclerosis are frequently observed in young patients early in the course of $\mathrm{T} \mathrm{DM}^{2,3)}$. Considering that atherosclerosis is a precursor of cerebrovascular disease (CVD) and subacute atherosclerosis exists in young patients with T1DM, young patients with T1DM should be managed as a very high risk group for premature atherosclerosis, especially coronary heart disease ${ }^{3,4)}$.

Furthermore, CVD risk factors in childhood correlate with abnormalities in surrogate markers of atherosclerosis and atherosclerotic lesions in pathology evaluation ${ }^{5-77}$. Several studies have demonstrated serum lipid abnormalities in children with T1DM as well as an association between elevated glycosylated hemoglobin ( $\mathrm{HbAlc}$ ) and serum lipid levels ${ }^{8-12)}$. These studies showed a high prevalence of dyslipidemia and the presence of CVD risk factors 
in youth with diabetes mellitus, including an association with elevated $\mathrm{HbAlc}$ and body mass index $(\mathrm{BMI})>90$ th percentile for age and gender ${ }^{11,13,14)}$.

Limited data are available on the prevalence of dyslipidemia and its association with glycemic control in Korean adolescents and young adults with T1DM. The objective of this study is to assess the lipid profiles and its association with glycemic control in this population.

\section{Materials and methods}

\section{Subjects}

From January 2013 to December 2013, we prospectively enrolled 29 patients who had been diagnosed with T1DM and visited the Department of Pediatrics, Yeouido St. Mary's Hospital. Inclusion criteria included patients with T1DM, age between 11 and 25 years, no other chronic illnesses, and no medications other than insulin. T1DM was defined by clinical parameters, including absolute need for insulin, young age of onset and history of ketosis, and presence of autoantibody ${ }^{15}$. The median age was 17 years (range, 10-25 years) and 18 patients $(62.1 \%)$ were female. Median duration of the disease was 7.5 years (range, $0.2-15.6$ years). The study was reviewed and approved by the local Institutional Review Board (IRB No. SC13OIS0086) that had jurisdiction over the local study populations, and all participants provided informed consent and/or assent.

\section{Data collection and definition}

During the study visit, survey information was collected and an examination was performed to measure systolic and diastolic blood pressures, height, weight, and BMI. BMI scores were calculated as weight $(\mathrm{kg}) /$ height $\left(\mathrm{m}^{2}\right)$ and expressed in $z$ scores, according to the standards assessed by the 2007 Korea National Growth Charts ${ }^{16)}$. Samples (blood glucose, HbAlc, total cholesterol [TC], low-density lipoprotein [LDL] cholesterol, high-density lipoprotein [HDL] cholesterol, and triglyceride [TG]) were obtained under conditions of metabolic stability after at least 8 hours of fasting. The mean value of two $\mathrm{HbAlc}$ levels measured within 6 months was used as a surrogate marker for recent glycemic control.

Cut points for abnormal lipid levels ( $\mathrm{TC} \geq 200 \mathrm{mg} / \mathrm{dL}$, LDL cholesterol $\geq 130 \mathrm{mg} / \mathrm{dL}$, HDL cholesterol $\leq 35 \mathrm{mg} / \mathrm{dL}$, and $\mathrm{TG} \geq 150 \mathrm{mg} / \mathrm{dL}$ ) were taken from the Third Report of the National Cholesterol Education Program ${ }^{17)}$ and the American Diabetes Association ${ }^{18)}$. Dyslipidemia was defined by the presence of one or more abnormal serum lipid concentrations. For the present cross-sectional analysis, clinical data, $\mathrm{HbAlc}$, BMI, and lipid profiles were investigated in adolescents and young adults with T1DM. We compared the lipid profiles of patients

Table 1. Clinical and laboratory variables in type 1 diabetes mellitus patients without and with dyslipidemia

\begin{tabular}{|c|c|c|c|c|}
\hline Characteristic & All patients $(n=29)$ & Patients without dyslipidemia $(n=18)$ & Patients with dyslipidemia $(n=11)$ & $P$-value \\
\hline Female gender & $18(62.1)$ & $9(50.0)$ & $9(81.8)$ & 0.181 \\
\hline Age at visit (yr) & $17(10-25)$ & $16.2(10-24.2)$ & $17.6(11-25)$ & 0.383 \\
\hline Age of diabetes diagnosis (yr) & $11.4(3.2-15.9)$ & $11.4(3.2-14.6)$ & $11.8(4.8-15.9)$ & 0.672 \\
\hline Duration of disease (yr) & $7.5(0.2-15.6)$ & $7.7(0.2-15.6)$ & $6.9(1.5-11.4)$ & 0.673 \\
\hline $\mathrm{HbA1c}(\%)$ & $8.3(6.6-12.3)$ & $8.0(6.6-10.0)$ & $10.6(7.5-12.3)$ & 0.002 \\
\hline Height & $163(134.5-181.5)$ & $160.6(146.9-180)$ & $164(134.5-181.5)$ & 0.803 \\
\hline Height, z score & $-0.1(-2.7$ to 2.5$)$ & $-1.95(-2.7$ to 1.9$)$ & $0.5(-1.2$ to 2.5$)$ & 0.751 \\
\hline Weight & $56.8(33.5-113)$ & $53.5(38.5-72)$ & $59(33.5-113)$ & 0.142 \\
\hline Weight, z score & $0.2(-3.6$ to 2.9$)$ & -0.1 ( -3.6 to 2.2$)$ & 0.7 (-0.1 to 2.9$)$ & 0.043 \\
\hline BMI, z score & $0.03(-2.5$ to 2.6$)$ & $-0.4(-2.5$ to 2.2$)$ & $0.7(-0.57$ to 2.6$)$ & 0.024 \\
\hline$\geq 1.0$ & $6(20.7)$ & $2(11.1)$ & $4(36.4)$ & 0.164 \\
\hline$\geq 2.0$ & $3(10.3)$ & $2(11.1)$ & $1(9.1)$ & $>0.973$ \\
\hline Serum C-peptide & $0.1(0.04-4.0)$ & $0.1(0.04-3.9)$ & $0.1(0.04-4.0)$ & 0.802 \\
\hline \multicolumn{5}{|l|}{ Lipid profiles } \\
\hline $\mathrm{TC}(\mathrm{mg} / \mathrm{dL})$ & $167(120-256)$ & $158(120-189)$ & $213(154-256)$ & $<0.001$ \\
\hline LDL cholesterol (mg/L) & $94(50-159)$ & $78(50-101)$ & $119(78-159)$ & $<0.001$ \\
\hline HDL cholesterol (mg/dL) & $51(28-108)$ & $48(38-88)$ & $52(28-108)$ & 0.813 \\
\hline $\mathrm{TG}(\mathrm{mg} / \mathrm{dL})^{\mathrm{a})}$ & $82(36-187)$ & $58(36-104)$ & $102(61-187)$ & $<0.001$ \\
\hline \multicolumn{5}{|l|}{ Microvascular complications } \\
\hline Microalbuminuria & $3(10.3)$ & $2(11.1)$ & $1(9.1)$ & 0.542 \\
\hline Retinopathy & $0(0)$ & $0(0)$ & $0(0)$ & NA \\
\hline Neuropathy & $1(0)$ & $0(0)$ & $1(3.3)$ & NA \\
\hline
\end{tabular}

Values are presented as number of cases (\%) or median (range).

HbA1c, hemoglobin A1c; BMI, body mass index; TC, total cholesterol; LDL cholesterol, low density lipoprotein cholesterol; HDL cholesterol, high density lipoprotein cholesterol; TG, triglyceride; NA, not applicable

a) These parameters are not available in one patient. 
with dyslipidemia and those without dyslipidemia.

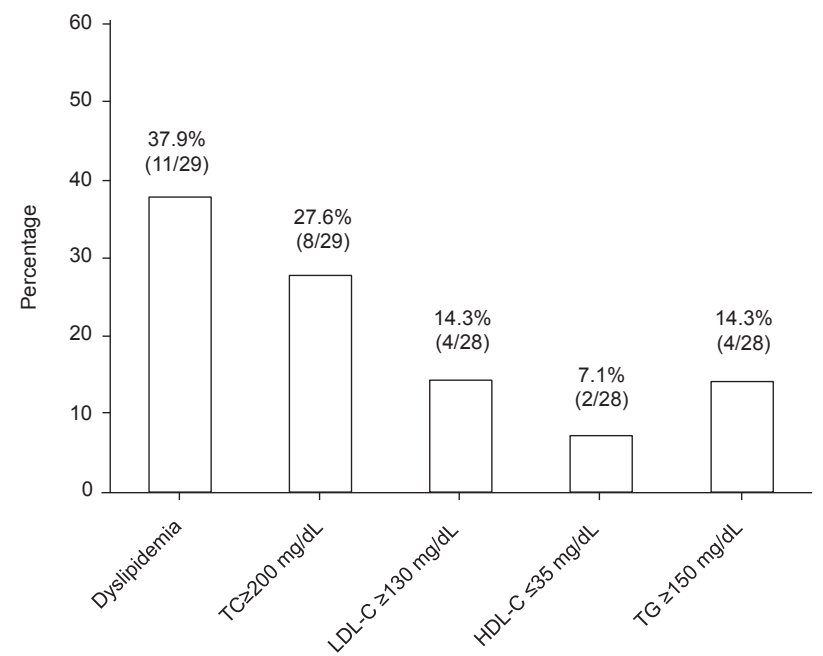

Fig. 1. Prevalence of dyslipidemia for patients with type 1 diabetes mellitus is shown. TC, total cholesterol; LDL-C, low-density lipoprotein cholesterol; HDL-C, high-density lipoprotein cholesterol; TG, triglyceride.
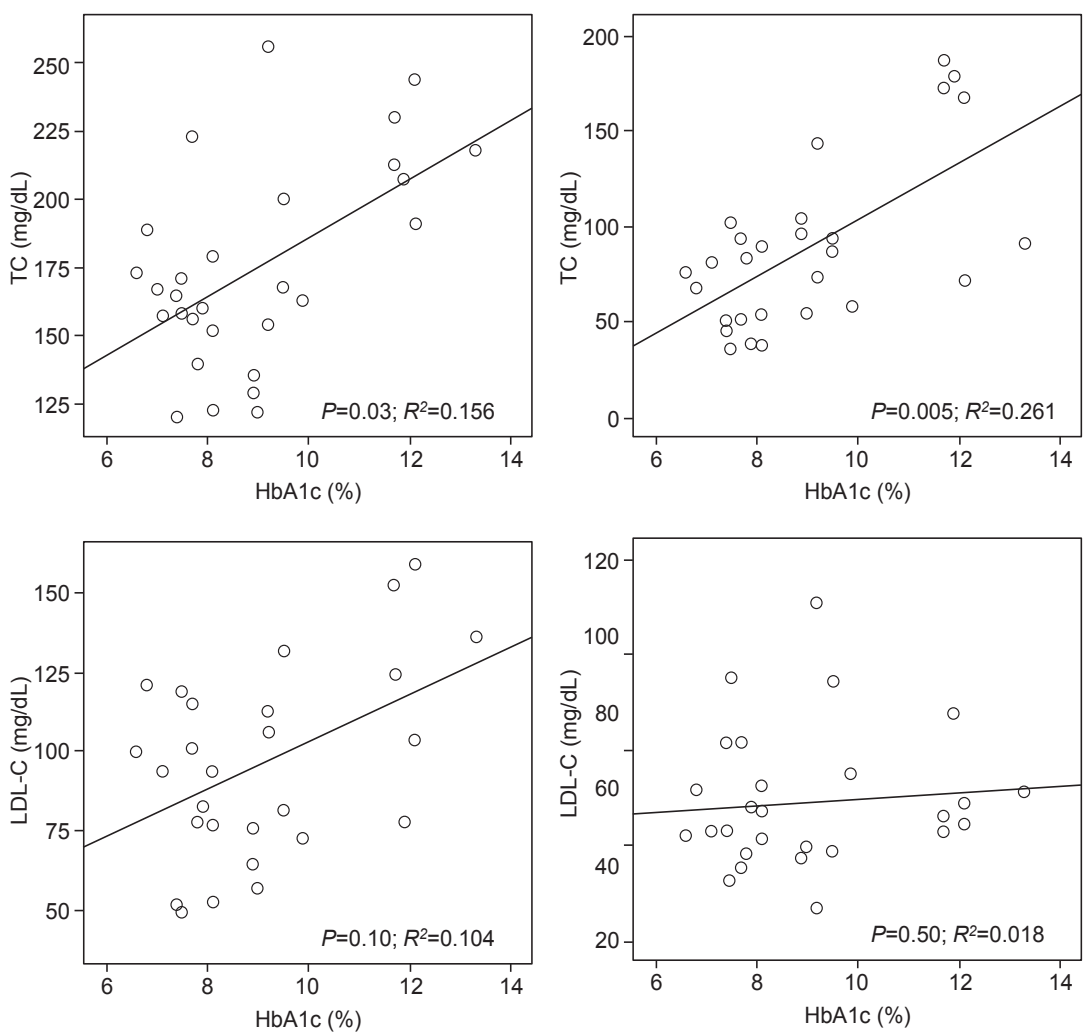

Fig. 2. Correlation between glycemic control parameters and plasma lipid variables is shown. $\mathrm{HbA1c}$, hemoglobin A1c; TC, total cholesterol; TG, triglyceride; LDL-C, low-density lipoprotein cholesterol; HDL-C, high-density lipoprotein cholesterol.
All statistical analyses were conducted with the use of PASW Statistics ver. 18 (SPSS Inc., Chicago, IL, USA). Nonparametric statistics were applied in the analysis of data with skewed distribution. Continuous variables are expressed as the median with ranges. Differences in the means of continuous variables were tested using the Mann-Whitney $U$ test. Differences in proportions were tested using the Fisher exact test. The Spearman rank correlation test was used to evaluate the correlation between continuous variables. To identify the independent risk factors for dyslipidemia, all variables significant in univariate analysis were included in a multiple logistic regression model. All $P$-values $<0.05$ were considered statistically significant.

\section{Results}

Table 1 shows the clinical and laboratory variables of T1DM patients with or without dyslipidemia. Median values for fasting lipid measures at the initial visit were as follows: TC, $167 \mathrm{mg} / \mathrm{dL}$ (range, 120-256 mg/dL); LDL-C, $94 \mathrm{mg} / \mathrm{dL}$ (range, 50-159 mg/ dL); HDL-C, $51 \mathrm{mg} / \mathrm{dL}$ (range, $28-108 \mathrm{mg} / \mathrm{dL}$ ); and TG, $82 \mathrm{mg} /$ dL (range, 36-187 mg/dL). Median HbAlc level of the patients was $8.1 \%$ (range, $6.6 \%-13.3 \%$ ). 
Of the 29 patients, 11 (37.9\%) were classified as having dyslipidemia due to the following lipid abnormality: TC $\geq 200$ $\mathrm{mg} / \mathrm{dL}$ in $27.6 \%$ (8/29 patients), LDL-C $\geq 130 \mathrm{mg} / \mathrm{dL}$ in $14.3 \%$ (4/28 patients), HDL-C $\leq 35 \mathrm{mg} / \mathrm{dL}$ in $7.1 \%$ (2/28 patients), and $\mathrm{TG} \geq 150 \mathrm{mg} / \mathrm{dL}$ in $14.3 \%$ (4/28 patients) (Fig. 1 ).

HbAlc of those patients without dyslipidemia was lower than that of patients with dyslipidemia (median, $8.0 \%$; range, $6.6 \%-10.0 \%$ vs. median, $10.6 \%$; range, $7.5 \%-12.3 \%$; $P=0.002$ ). The BMI $z$ score of T1DM patients without dyslipidemia was lower than that of patients with dyslipidemia (median, -0.4 ; range, -2.5 to 2.2 vs. median, 0.7 ; range, -0.57 to 2.6 ; $P=0.02$ ). Although dyslipidemia was more common in females than in males, this finding did not reach the statistical significance (50.0\% [9/18 patients] vs. $18.2 \%$ [ $2 / 11$ patients]; $P=0.18$ ). There were no differences in age, disease duration, and microvascular complications between the dyslipidemia and no dyslipidemia groups.

The correlation between glycemic control parameters and plasma lipid variables is shown in Fig. 2. A significant positive correlation was found between $\mathrm{HbAlc}$ and TC $(P=0.03$, $\left.R^{2}=0.156\right)$ and TG $\left(P=0.005, R^{2}=0.261\right)$. HbAlc showed no correlation with LDL-C or HDL-C. Multivariate logistic regression analysis indicated that $\mathrm{HbAlc}$ was the only independent risk factor for dyslipidemia (adjusted odds ratio, $3.11 ; 95 \%$ confidence interval, $1.35-7.40 ; P=0.01$ ).

To evaluate the association between lipid values and glycemic control, we categorized patients into two groups using the median value of HbAlc (8.3\%) at the time of the study (Table 2). Patients with $\mathrm{HbAlc} \geq 8.3 \%$ showed a higher incidence of dyslipidemia compared to those with HbAlc $<8.3 \%$ (64.3\% [ $9 / 15$ patients] vs. $13.3 \%$ [2/15 patients]; $P=0.008$ ). There were no differences in age, sex, BMI $z$ scores, and disease duration between the two groups.

\section{Discussion}

To the best of our knowledge, this study is the first to evaluate the serum lipid profiles and glycemic control in Korean adolescents and young adults with type 1 diabetes. We found that more than one third of Korean adolescents and young adults with T1DM had dyslipidemia, which was significantly associated with a higher HbAlc levels and BMI $z$ scores.

In recent studies, the prevalence of dyslipidemia was shown to be $19.7 \%$ of Korean healthy children and adolescents ${ }^{19)}$ and $44.1 \%$ in Korean healthy adults ${ }^{20)}$. The overall prevalence of dyslipidemia among adolescents and young adults with T1DM in this study was $37.9 \%$. This prevalence is higher than the 28.6\% observed in German and Austrian adolescents and young adults with $\mathrm{T}_{1} \mathrm{DM}^{21)}$ and comparable to the $39.2 \%$ in England children with $\mathrm{T}_{1 \mathrm{DM}}{ }^{10)}$. Therefore, we found high prevalence of dyslipidemia in Korean adolescents and young adults with T1DM. This finding has potential clinical significance, given the well-known relationship between dyslipidemia and cardiovascular events and the fact that lipid levels frequently track from childhood to adulthood ${ }^{22)}$.

Our study showed that HbA1c levels were positively correlated with TC and TG. In a previous study, a positive correlation was found between HbAlc and TC, and TG in children with $\mathrm{T}_{1 \mathrm{DM}}{ }^{10)}$. Maahs et al. ${ }^{23)}$ performed a retrospective analysis of subjects with T1DM by analyzing random lipid levels measured during clinical practice. Their study showed a positive association between HbAlc and both TC and non-HDL-C. Guy et al. ${ }^{13)}$ reported cross sectional data from the SEARCH for Diabetes in Youth (SEARCH) study, in which T1DM subjects with a HbAlc target $<7.5 \%$ had lower prevalence of dyslipidemia, similar to healthy controls, while T1DM subjects with $\mathrm{HbA} 1 \mathrm{c} \geq 7.5 \%$ were more likely to have elevated TC and LDL-C levels. A positive correlation between $\mathrm{HbAlc}$ and serum lipids has been demonstrated in other cross sectional studies, providing indirect evidence for a beneficial effect of glycemic control on serum lipids in children and young adults ${ }^{11,24)}$. The SEARCH study including 1,193 United States children with T1DM reported lower frequency of lipid abnormalites ${ }^{25}$ ) compared to our study and the studies previously described ${ }^{10,21)}$. In the SEARCH study, the incidence of $\mathrm{TC} \geq 200 \mathrm{mg} / \mathrm{dL}$, LDL-C $\geq 130 \mathrm{mg} / \mathrm{dL}, \mathrm{HDL}-\mathrm{C} \leq 35 \mathrm{mg} / \mathrm{dL}$ and $\mathrm{TG} \geq 150 \mathrm{mg} / \mathrm{dL}$ was $8.4 \%, 7.2 \%, 4.7 \%$, and $2.9 \%$, respectively ${ }^{25)}$. Mean HbAlc of the subjects included in the SEARCH study was 7.7\%, which

Table 2. Lipid profiles according to glycemic control in patients with type 1 diabetes mellitus

\begin{tabular}{|c|c|c|c|}
\hline Variable & $\mathrm{HbA1c}<8.3 \%(\mathrm{n}=14)$ & $\mathrm{HbA1c} \geq 8.3 \%(n=15)$ & $P$-value \\
\hline Age (yr) & $14.7(10.8-23)$ & $18.3(10-25)$ & 0.142 \\
\hline Female gender & $9(64.3)$ & $9(60)$ & 0.812 \\
\hline $\mathrm{BMI}$, z score & $-0.3(-1.3$ to 2.6$)$ & $0.19(-2.5$ to 1.9$)$ & 0.324 \\
\hline Disease duration (yr) & $8.6(0.2-15.6)$ & $6.9(1.5-12.7)$ & 0.681 \\
\hline \multicolumn{4}{|l|}{ Lipid profiles } \\
\hline $\mathrm{TC} \geq 200 \mathrm{mg} / \mathrm{dL}$ & $1(7.1)$ & $7 / 15(46.7)$ & 0.013 \\
\hline LDL cholesterol $\geq 130 \mathrm{mg} / \mathrm{dL}$ & $0(0)$ & $4 / 15(26.7)$ & 0.098 \\
\hline HDL cholesterol $\leq 35$ mg/dL & $2(14.3)$ & $1 / 14(7.1)$ & $>0.934$ \\
\hline $\mathrm{TG} \geq 150 \mathrm{mg} / \mathrm{dL}$ & $0(0)$ & $4 / 14(28.6)$ & 0.098 \\
\hline Dyslipidemia (any of the above abnormalities) & $3(21.4)$ & $8 / 15(53.3)$ & 0.008 \\
\hline
\end{tabular}

Values are presented as median (range) or number of cases (\%).

HbA1c, hemoglobin A1c; BMI, body mass index; TC, total cholesterol; LDL cholesterol, low-density lipoprotein cholesterol; HDL cholesterol, high-density lipoprotein cholesterol; TG, triglyceride. 
was lower compared to the level of our study (8.9\%) and other sudies $^{10,21)}$. This findings support the importance of glycemic control as a determinant of and a potential modifiable risk factor for dyslipidemia.

Our data were equivocal regarding the association between dyslipidemia and BMI $z$ scores. Although in the univariate analysis, BMI $z$ scores were associated with dyslipidemia, this association was lost after controlling for $\mathrm{HbAlc}$ in the multivariate logistic regression analysis. The association between being overweight and an adverse lipid profile has been documented in subjects with T1DM ${ }^{21,23,26}$. In the DCCT (The Diabetes Control and Complications Trial) cohort, excessive weight gain was related to dyslipidemia and declines in $\mathrm{HbAlc}$ were associated with improvements in lipid levels only in subjects with the least weight gain during the interventional period $^{27)}$. These observations may be partly explained by the insulin resistance and hyperinsulinemia associated with increased body weight ${ }^{28)}$. In this study, we could not conclude whether or not BMI $z$ scores were independently associated with dyslipidemia because of the small number of cases of dyslipidemia and overweight patients. However, on the basis of the findings from out study and those of previous studies ${ }^{21,23,26,27}$, maintenance of healthy weight during adolescent and young adult periods may be important to normalize lipid profiles and reduce subsequent risks of CVDs. Further studies including large numbers of patients should be performed to clarify for this issue.

In our study, there was a trend towards a higher prevalence of dyslipidemia in T1DM in females than in males, which is in line with previous data ${ }^{29)}$. Our findings might be partly explained by the different degrees of insulin resistance between the two sexes or a direct effect of hormonal status on enzymes implicated in lipoprotein metabolism ${ }^{21,28)}$.

In addition, increased testosterone levels have been shown to be negatively associated with TC, LDL-C, and HDL-C levels ${ }^{30}$. In another study, as the testosterone/estradiol ratio decreased, LDL-C, and HDL-C levels increased ${ }^{311}$.

This study has several limitations. First, repeated measurements of fasting lipids were not made over time in individual subjects. Second, the number of patients included was small compared with the number of risk factors evaluated; thus, compromising the power of both the univariate and the multivariate analyses.

In conclusion, our study is the first report of lipid data in Korean adolescents and young adults with T1DM. We showed a substantial proportion of adolescents and young adults with TIDM had dyslipidemia, and dyslipidemia in this population was associated with poor glycemic control. Given that dyslipidemia is a potentially modifiable CVD risk factor, further studies should be aimed to evaluate the optimal approach for early diagnosis and effective treatment of dyslipidemia among adolescent and young adults with T1DM.

\section{Conflict of interest}

No potential conflict of interest relevant to this article was reported.

\section{References}

1. Maahs DM, Wadwa RP, Bishop F, Daniels SR, Rewers M, Klingensmith GJ. Dyslipidemia in youth with diabetes: to treat or not to treat? J Pediatr 2008;153:458-65.

2. Jarvisalo MJ, Putto-Laurila A, Jartti L, Lehtimaki T, Solakivi $\mathrm{T}$, Ronnemaa $\mathrm{T}$, et al. Carotid artery intima-media thickness in children with type 1 diabetes. Diabetes 2002;51:493-8.

3. Krantz JS, Mack WJ, Hodis HN, Liu CR, Liu CH, Kaufman FR. Early onset of subclinical atherosclerosis in young persons with type 1 diabetes. J Pediatr 2004;145:452-7.

4. Newman WP 3rd, Freedman DS, Voors AW, Gard PD, Srinivasan SR, Cresanta JL, et al. Relation of serum lipoprotein levels and systolic blood pressure to early atherosclerosis. The Bogalusa Heart Study. N Engl J Med 1986;314:138-44.

5. Berenson GS, Srinivasan SR, Bao W, Newman WP 3rd, Tracy RE, Wattigney WA. Association between multiple cardiovascular risk factors and atherosclerosis in children and young adults. The Bogalusa Heart Study. N Engl J Med 1998:338:1650-6.

6. Raitakari OT, Juonala M, Kahonen M, Taittonen L, Laitinen T, Maki-Torkko N, et al. Cardiovascular risk factors in childhood and carotid artery intima-media thickness in adulthood: the Cardiovascular Risk in Young Finns Study. JAMA 2003;290:2277-83.

7. Juonala M, Jarvisalo MJ, Maki-Torkko N, Kahonen M, Viikari JS, Raitakari OT. Risk factors identified in childhood and decreased carotid artery elasticity in adulthood: the Cardiovascular Risk in Young Finns Study. Circulation 2005; 112:1486-93.

8. Shamir R, Kassis H, Kaplan M, Naveh T, Shehadeh N. Glycemic control in adolescents with type 1 diabetes mellitus improves lipid serum levels and oxidative stress. Pediatr Diabetes 2008;9:104-9.

9. Bustos P, Radojkovic C, Ulloa N, Munoz M, Martinez A, Calvo C, et al. Lipoprotein composition in children and adolescents with type 1 diabetes mellitus. J Pediatr Endocrinol Metab 2005; 18:257-64.

10. Azad K, Parkin JM, Court S, Laker MF, Alberti KG. Circulating lipids and glycaemic control in insulin dependent diabetic children. Arch Dis Child 1994;71:10813 .

11. Ladeia AM, Adan L, Couto-Silva AC, Hiltner A, Guimaraes AC. Lipid profile correlates with glycemic control in young patients with type 1 diabetes mellitus. Prev Cardiol 2006;9:82-8.

12. Gunczler P, Lanes R, Soros A, Verdu L, Ramon Y, Guevara $\mathrm{B}$, et al. Coronary artery calcification, serum lipids, lipoproteins, and peripheral inflammatory markers in 
adolescents and young adults with type 1 diabetes. J Pediatr 2006;149:320-3.

13. Guy J, Ogden L, Wadwa RP, Hamman RF, Mayer-Davis EJ, Liese AD, et al. Lipid and lipoprotein profiles in youth with and without type 1 diabetes: the SEARCH for Diabetes in Youth case-control study. Diabetes Care 2009;32:416-20.

14. Rodriguez BL, Fujimoto WY, Mayer-Davis EJ, Imperatore G, Williams DE, Bell RA, et al. Prevalence of cardiovascular disease risk factors in U.S. children and adolescents with diabetes: the SEARCH for diabetes in youth study. Diabetes Care 2006;29:1891-6.

15. American Diabetes Association. Diagnosis and classification of diabetes mellitus. Diabetes Care 2008;31 Suppl 1:S55-60.

16. Moon JS, Lee SY, Nam CM, Choi JM, Choe BK, Seo JW, et al. 2007 Korean National Growth Charts: review of developmental process and an outlook. Korean J Pediatr 2008;51:1-25.

17. Expert Panel on Detection, Evaluation, and Treatment of High Blood Cholesterol in Adults. Executive Summary of The Third Report of The National Cholesterol Education Program (NCEP) Expert Panel on Detection, Evaluation, And Treatment of High Blood Cholesterol In Adults (Adult Treatment Panel III). JAMA 2001;285:2486-97.

18. American Diabetes Association. Management of dyslipidemia in children and adolescents with diabetes. Diabetes Care 2003;26:2194-7.

19. Yang S, Hwang JS, Park HK, Lee HS, Kim HS, Kim EY, et al. Serum lipid concentrations, prevalence of dyslipidemia, and percentage eligible for pharmacological treatment of Korean children and adolescents; data from the Korea National Health and Nutrition Examination Survey IV (2007-2009). PLoS One 2012;7:e49253.

20. Lee MH, Kim HC, Ahn SV, Hur NW, Choi DP, Park CG, et al. Prevalence of dyslipidemia among Korean Adults: Korea National Health and Nutrition Survey 1998-2005. Diabetes Metab J 2012;36:43-55.

21. Schwab KO, Doerfer J, Hecker W, Grulich-Henn J, Wiemann D, Kordonouri O, et al. Spectrum and prevalence of atherogenic risk factors in 27,358 children, adolescents, and young adults with type 1 diabetes: cross-sectional data from the German diabetes documentation and quality management system (DPV). Diabetes Care 2006;29:218-25.
22. Libby P, Nathan DM, Abraham K, Brunzell JD, Fradkin JE, Haffner SM, et al. Report of the National Heart, Lung, and Blood Institute-National Institute of Diabetes and Digestive and Kidney Diseases Working Group on Cardiovascular Complications of Type 1 Diabetes Mellitus. Circulation 2005;111:3489-93.

23. Maahs DM, Wadwa RP, McFann K, Nadeau K, Williams $\mathrm{MR}$, Eckel RH, et al. Longitudinal lipid screening and use of lipid-lowering medications in pediatric type 1 diabetes. J Pediatr 2007; 150:146-50, 150.e1-2.

24. al Muhtaseb N, al Yousuf A, Bajaj JS. Apolipoprotein A-I, A-II, B, C-II, and C-III in children with insulin-dependent diabetes mellitus. Pediatrics 1992;89(5 Pt 1):936-41.

25. Maahs DM, Dabelea D, D'Agostino RB Jr, Andrews JS, Shah AS, Crimmins N, et al. Glucose control predicts 2-year change in lipid profile in youth with type 1 diabetes. J Pediatr 2013;162:101-7.e1.

26. Maahs DM, Maniatis AK, Nadeau K, Wadwa RP, McFann K, Klingensmith GJ. Total cholesterol and high-density lipoprotein levels in pediatric subjects with type 1 diabetes mellitus. J Pediatr 2005;147:544-6.

27. Purnell JQ, Hokanson JE, Marcovina SM, Steffes MW, Cleary PA, Brunzell JD. Effect of excessive weight gain with intensive therapy of type 1 diabetes on lipid levels and blood pressure: results from the DCCT. Diabetes Control and Complications Trial. JAMA 1998;280:140-6.

28. Jenkins AJ, Lyons TJ, Zheng D, Otvos JD, Lackland DT, McGee D, et al. Lipoproteins in the DCCT/EDIC cohort: associations with diabetic nephropathy. Kidney Int 2003;64:817-28.

29. Marcovecchio ML, Dalton RN, Prevost AT, Acerini CL, Barrett TG, Cooper JD, et al. Prevalence of abnormal lipid profiles and the relationship with the development of microalbuminuria in adolescents with type 1 diabetes. Diabetes Care 2009;32:658-63.

30. Garces C, Oya Id, Lasuncion MA, Lopez-Simon L, Cano B, de Oya M. Sex hormone-binding globulin and lipid profile in pubertal children. Metabolism 2010;59:166-71.

31. Laskarzewski PM, Morrison JA, Gutai J, Khoury PR, Glueck CJ. Longitudinal relationships among endogenous testosterone, estradiol, and Quetelet index with high and low density lipoprotein cholesterols in adolescent boys. Pediatr Res 1983;17:689-98. 